\title{
BMJ Open The possibility of lifestyle and biological risk markers to predict morbidity and mortality in a cohort of young men after 26 years follow-up
}

\author{
Lars-Göran Persson, ${ }^{1}$ Hans Lingfors, ${ }^{1}$ Mats Nilsson, ${ }^{2}$ Sigvard Mölstad ${ }^{3}$
}

To cite: Persson L-G, Lingfors $\mathrm{H}$, Nilsson $\mathrm{M}$, et al. The possibility of lifestyle and biological risk markers to predict morbidity and mortality in a cohort of young men after 26 years follow-up. BMJ Open 2015;5: e006798. doi:10.1136/ bmjopen-2014-006798

- Prepublication history for this paper is available online. To view these files please visit the journal online (http://dx.doi.org/10.1136/ bmjopen-2014-006798).

Received 7 October 2014 Revised 2 April 2015 Accepted 11 April 2015

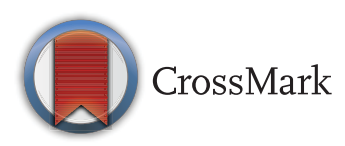

${ }^{1}$ Futurum, Health Care Centre of Habo and Unit for Research and Development in Primary Health Care, Jönköping, Sweden

${ }^{2}$ Primary Health Care, Futurum County Council of Jönköping, Jönköping, Sweden

${ }^{3}$ Department of Clinical Sciences, General Practice, Lund University, Malmö, Sweden

Correspondence to Dr Lars-Göran Persson; Lars-goran.persson@rjl.se

\section{ABSTRACT}

Objectives: To study the association between lifestyle and biological risk markers measured at one occasion, morbidity and mortality from cardiovascular disease (CVD) and cancer, and morbidity from diabetes approximately 26 years later.

Design: A follow-up study of a cohort of men, 33-42 years old at baseline.

Setting: Primary healthcare centre in Sweden. Participants: All 757 men, living in the community of Habo in Sweden in 1985, and all 652 of these participating in a health examination in 1985-1987.

Interventions: Health profile and a health dialogue with a nurse. A doctor invited the high-risk group to further dialogue and examination. Intervention programmes were carried out in the primary healthcare centre and in cooperation with local associations.

Main outcome measures: CVD and cancer diagnoses from the Swedish National Board of Health and Welfare. Data from pharmacy registers of sold drugs concerning diabetes mellitus.

Results: The participants were divided in three groups based on summarised risk points from lifestyle (smoking, physical activity, alcohol consumption) and biological risk markers (body mass index (BMI), blood pressure, serum cholesterol) selected from the health profile. Comparisons were done between these groups. The group with the lowest summarised total risk points had a significantly lower risk for CVD and cancer compared with the group with the highest summarised risk points. The group with the lowest risk points concerning lifestyle had a significantly lower risk for CVD, and the group with lowest risk points for biological risk markers had a significantly lower risk for both CVD and cancer compared with the groups with the highest risk points. Smoking and serum cholesterol were the most important risk factors. In association to diabetes, BMI and smoking were the most important risk factors.

Conclusions: Risk factors measured on one occasion seemed to be able to predict CVD, cancer and diabetes 26 years later.

\section{INTRODUCTION}

Cardiovascular disease (CVD) is the most common cause of total mortality and

\section{Strengths and limitations of this study}

- A long follow-up time of a cohort of rather young men with a high participating rate in the baseline health examination. Few other studies have focused on this young group earlier, especially in primary healthcare.

- Individual data concerning morbidity and mortality from cardiovascular disease and cancer from registers belonging to the Swedish Board of Health and Welfare. Individual register data of sold drugs for treatment of diabetes mellitus. All data from the baseline examination and these two registers were based on personal code number.

- The cohort is rather small and many men could have probably changed lifestyle and biological risk markers during follow-up time.

- Other risk factors can also influence the risk for these diseases, for example, food habits. In the baseline examination, there were only a few questions concerning food habits and these were not indexed in the health profile.

premature death (before 75 years of age) in Sweden as well as in other Western countries. ${ }^{12}$ The incidence of diabetes mellitus is rapidly increasing worldwide, and diabetes is linked to CVD. According to the INTERHEART study, more than $90 \%$ of the risk for acute myocardial infarction could be explained by nine modifiable risk factors, among them diabetes, several of them being lifestyle factors. ${ }^{3}$ The same factors in addition to cardiac disease were associated to $90 \%$ of stroke in the INTERSTROKE study. ${ }^{4}$ Lifestyle is also related to risk for cancer. ${ }^{5}{ }^{6}$ Some kind of global risk assessment can be used to estimate the risk for future death in CVD. SCORE (Systematic COronary Risk Evaluation) is one such risk assessment system for estimation of 10 -year risk of fatal CVD, developed by the European Society of Cardiology (ESC) and modified for use in Sweden. ${ }^{7}$ SCORE is also recommended by ESC for use in Sweden and other European countries. ${ }^{9}$ 
Another kind of risk assessment tool, a pedagogic health profile, was developed and used in a primary prevention programme for men, 33-42 years of age, in the community of Habo in Sweden. Each of the 10 risk factors considered being most important for CVD and cancer was graded in four or five levels. ${ }^{10}$ Seven of these risk factors are the same as in the later INTERHEART study.

Rather few studies concerning cohorts of men younger, and a little older, than 40 years with a follow-up time of more than 20 years have been published. The study of male British doctors and a Finnish study of business executives, with follow-up time of 50 and 32 years, respectively, are examples of studies with unusually long follow-up time. $^{11}{ }^{12}$ The follow-up of the male British doctors showed a progressive decrease in mortality rates among non-smokers in relation to continuous smokers. On group level, the continuous smokers lost 10 years of life. The Finnish study showed that among men who smoked and had a baseline serum cholesterol $>6.5 \mathrm{mmol} / \mathrm{L}$, the risk of death increased progressively with systolic blood pressure.

The men in the Whitehall study and the 23-year mortality follow-up study in Israel were 40 years and above. ${ }^{13} 14$ In the 38-year follow-up of the Whitehall study, there was a risk score based on smoking, diabetes, employment grade, blood pressure, serum cholesterol and body mass index (BMI). Men in the highest $5 \%$ risk score had a 15 -year shorter life expectancy compared with men in the lowest $5 \%$ risk score. The Israel study showed that a number of established risk factors for cardiac heart disease (CHD), among them a single casual assessment of blood pressure, could predict mortality.

To our knowledge, no studies on a cohort of men as young as in our study have been organised and carried out in primary care with a follow-up time of more than 20 years. The British Regional Heart Study included men 40-59 years from 24 primary healthcare centres, but it was organised from University institutions. ${ }^{15}$
The principal aim of this study is to test the ability of lifestyle and biological risk markers measured in young men on one occasion to predict morbidity and mortality from CVD, and cancer, and morbidity from diabetes approximately 26 years after the initial examination. Another aim is to study CVD, cancer and mortality in the non-participant group, and compare with the participants.

\section{METHODS}

\section{Baseline examination}

In 1985, all 757 men aged 33-42 years, living in the community of Habo in Sweden were invited to a health examination and health dialogue, which was carried out in 1985-1987. In total, 652 men attended (participation rate $86 \%$ ). A questionnaire was used which included questions about personal history of CVD and diabetes, prevalence of mental symptoms, lifestyle, stress and social network. Most of the questions had been included in questionnaires used in previous studies. The biological risk markers measured were: BMI, blood pressure, serum cholesterol, serum triglycerides and blood glucose. The lifestyle factors were: smoking, self-reported physical activity and alcohol consumption. ${ }^{16}$ The results from the questionnaire and measurements were included in a pedagogic health profile. Ten risk factors considered being most important for CVD and cancer were graded in 1-5 risk points. ${ }^{10}$ Self-estimated physical activity during leisure time and self-estimated mental stress were graded in 1-4 risk points, and hereditary for diabetes mellitus in 0,4 or 5 risk points.

The design of this health profile and ranges denoting risk points are shown in table 1.

\section{Explanations}

Heredity death: Highest risk point for father or mother registered (except for accidents or infections).

Table 1 Health profile showing limits for classification into different risk groups (risk points)

\begin{tabular}{|c|c|c|c|c|c|c|}
\hline \multirow[t]{2}{*}{ Risk factor studied } & & \multicolumn{5}{|c|}{ Risk points } \\
\hline & & 1 & 2 & 3 & 4 & 5 \\
\hline \multirow{2}{*}{$\begin{array}{l}\text { Age (years) at death of father or mother if } \\
\text { dead }\end{array}$} & Father & $\geq 95$ & 70-94 & $60-69$ & $50-59$ & $<50$ \\
\hline & Mother & $\geq 95$ & $75-94$ & $65-74$ & $55-64$ & $<55$ \\
\hline $\begin{array}{l}\text { Number of diabetics among parents or } \\
\text { siblings }\end{array}$ & & - & - & - & 1 & $\geq 2$ \\
\hline Use of alcohol (g per week) & & 0 & $1-49$ & $50-109$ & 110-249 & $\geq 250$ \\
\hline Smoking (g tobacco per day) & & 0 & ex-smoker & $1-14$ & $15-24$ & $\geq 25$ \\
\hline $\begin{array}{l}\text { Physical exercise during leisure time } \\
\text { (self-estimation) }\end{array}$ & & 1 & 2 & 3 & 4 & - \\
\hline Mental stress (self-estimation) & & $<40$ & $40-69$ & $70-89$ & $\geq 90$ & - \\
\hline Mental health (estimation by nurse) & & 1 & 2 & 3 & 4 & 5 \\
\hline BMI $\left(\mathrm{kg} / \mathrm{m}^{2}\right)$ & & $<20$ & $20-24$ & $25-29$ & $30-39$ & $\geq 40$ \\
\hline \multirow[t]{2}{*}{ Arterial blood pressure $(\mathrm{mm} \mathrm{Hg})$} & $<40$ years & $\leq 140 /<85$ & $>140 />85$ & $>155 />90$ & $>160 />95$ & $>170 />105$ \\
\hline & $\geq 40$ years & $\leq 150 /<90$ & $>150 />90$ & $>160 />95$ & $>170 />95$ & $>180 />115$ \\
\hline Serum cholesterol (mmol/L) & & $<4.6$ & $4.6-5.9$ & $6.0-7.7$ & $7.8-9.5$ & $\geq 9.6$ \\
\hline
\end{tabular}


Physical exercise during leisure time: Risk point 1 means regular hard physical training and competition, and risk point 4 means physically inactive leisure time. ${ }^{16}$

Mental stress: Visual analogue scale, $\mathrm{mm}(0-100)$.

Mental health: According to judgement by nurse, 1 means good mental health, 4 means need of group therapy with muscular relaxation and 5 means need for individual contact with a doctor or a psychologist.

Arterial blood pressure: Highest risk point for systolic or diastolic blood pressure registered.

This health profile served as a pedagogic tool in a health dialogue with a specially trained nurse. The main aim of this health dialogue was to improve lifestyle in a patient-centred way. The health profile was also used to categorise the men in a high-risk and a low-risk group according to specially defined criteria, based on both lifestyle and biological risk markers. ${ }^{17}$ All men in the high-risk group were invited to see a doctor for further discussion about risk factors and how to lower these mainly through non-pharmacological measures. The doctor decided if complementary tests and pharmacological treatment were to be recommended. Specially designed intervention programmes were recommended to those with high-risk points. The intervention programmes were carried out in the primary healthcare centre and in cooperation with local associations. As intervention, all participants had a health dialogue with a nurse, and besides this altogether 418 men of the 652 men who attended the health examination were recommended some kind of intervention measures.

The baseline examination and the results after 1-year follow-up have been described earlier. ${ }^{17}$ In the baseline study, a rather thorough examination of the $105(14 \%)$ non-participants was carried out through a telephone interview, study of medical records and information from different registers. ${ }^{10}$

In the present follow-up study, only some of the baseline risk factors from the health profile are used as predictive factors. These are the lifestyle factors: smoking, alcohol consumption and self-estimated physical activity, and the biological risk markers: serum cholesterol, blood pressure and BMI.

\section{Follow-up study}

Data from all 757 men were gathered from registers at the Swedish National Board of Health and Welfare concerning CVDs. International Classification of Diseases (ICD) was used, ICD-9 diagnoses until 1997 were: 410, 411, 431-6 and ICD-10 diagnoses from 1997 were: G45, I21-22, I61, I63-66 and FN. Register data concerning cancer were diagnose, time of death and causes of death. Data from the register of patients treated in hospital, and causes of mortality were available up to 2013, and cancer data up to 2012. All CVD diagnoses and all cancer diagnoses, including death from CVD and cancer, respectively, were grouped together. This gave two groups: those men who at least once had got a cardiovascular diagnose or a cancer diagnoses and those who had not got such diagnose. Data were also gathered from pharmacy register of sold drugs concerning diabetes mellitus with Anatomical Therapeutic Chemical Classification (ATC) codes A10A and A10B during 2013.

\section{Statistical methods}

Descriptive results are presented as numbers and percentages. To evaluate different health/risk factors univariable logistic regression was used. As outcome CVD or cancer including death was used. As explanatory variables biological and lifestyle factors as well as summarised risk points, calculated from the health profile, were used. Results are presented as ORs with $95 \%$ CIs. If the $\mathrm{CI}$ includes one, then the results are considered to be non-significant from a statistical point of view. SAS statistical software has been used for the analysis.

\section{RESULTS}

In the follow-up of mortality 1987-2012 of the whole cohort of 757 men, 69 men (9\%) had died, 49 (8\%) participants and $20(19 \%)$ in the non-participant group. The most frequent causes were death from cancer and CVD (26 and 23 men, respectively). There was a significant increased total mortality among the nonparticipants in relation to the participants with OR 2.90 (CI 1.58 to 5.28). Comparing participants and nonparticipants, there was no significant increase in mortality of either CVD or cancer.

In the baseline examination performed in 1985-1987 of the 652 participants, one man had had a myocardial infarction, none had had a stroke, five men had diabetes mellitus, and four of these were treated with insulin and had probably diabetes type 1 . In the follow-up register study of the 652 men who participated in the baseline examination, there were 51diagnosed myocardial infarctions, 36 stroke (ischaemic or haemorrhagic) and 40 percutaneous coronary intervention or by-pass operations. In total, there were 91 men with at least one diagnosed CVD. There were 93 men among the participants who had got a cancer diagnose. The most frequent forms were cancer in prostate, skin and gastrointestinal canal with 33, 13 and 11 cases, respectively.

Logistic regression analyses were performed in several comparisons where the men were divided in risk groups according to the risk points in the health profile (table 1). The risk points for the baseline lifestyle (smoking, alcohol consumption and self-estimated physical exercise) and biological risk markers (blood pressure, serum cholesterol and BMI) used in the follow-up analysis were summarised and divided in three groups, 9-14 (low-risk group, 162 men), 15-18 (medium-risk group, 326 men) and 19-29 (high-risk group164 men). The risk points for lifestyle and biological risk makers were also divided in the groups with summarised risk points $3-5$, 6-8 and 9-14, respectively. The number of men in the different lifestyle groups was 140, 358 and 154, and in the biological risk marker groups 257, 337 and 58 . 
These different groups and separate lifestyle and biological risk markers were compared and analysed in association to CVD (table 2).

The groups with lowest summarised total risk points and lowest separate summarised risk points for lifestyle and biological risk markers had a significantly lower risk for fatal and non-fatal CVD, compared with the groups with highest summarised risk points. Concerning single risk factors smoking and high serum cholesterol $\geq 4.6 \mathrm{mmol} / \mathrm{L}$ were associated with a significantly higher risk for CVD.

The same groups were analysed in association to cancer (table 3).

The group with the lowest total summarised risk points and the group with lowest summarised risk points for biological risk markers had a significant lower risk for cancer compared with the group with the highest summarised risk points. The comparisons between the lifestyle groups were nearly significant. None of the single individual lifestyle or biological risk markers was significantly associated with cancer.

The number of men with medication for diabetes (insulin and/or tablets) was $58(8 \%)$. In table 4, the same individual risk factors are analysed in association to diabetes mellitus.

Men who were smokers, and especially men with BMI $\geq 25$, had a significantly increased risk for diabetes mellitus.
Table 3 Risk reduction presented as OR and $95 \% \mathrm{Cls}$ for cancer inclusive death

\begin{tabular}{lcc}
\hline Cancer & OR & 95\% Cls \\
\hline $\begin{array}{l}\text { Summarised risk points in the health profile } \\
\text { Low-risk vs high-risk group }\end{array}$ & 0.34 & 0.17 to 0.70 \\
$\quad \begin{array}{l}\text { Middle-risk vs high-risk group } \\
\text { Lifestyle risk factors }\end{array}$ & 0.78 & 0.48 to 1.28 \\
$\quad$ Low-risk vs high-risk group & 0.55 & 0.28 to 1.07 \\
$\quad$ Middle-risk vs high-risk group & 0.62 & 0.37 to 1.02 \\
$\begin{array}{l}\text { Biological risk factors } \\
\quad \text { Low-risk vs high-risk group }\end{array}$ & 0.37 & 0.18 to 0.79 \\
$\quad$ Middle-risk vs high-risk group & 0.67 & 0.34 to 1.32 \\
\hline
\end{tabular}

The data are presented as comparisons between different groups, according to summarised selected risk points (lifestyle plus biological risk factors) in the health profile (low-risk 9-14, middle-risk 15-18 and high-risk group 19-29 risk points), summarised lifestyle or biological risk markers (low-risk 3-5, middle-risk 6-8 and least favourable group 9-14 risk points). If the $\mathrm{Cl}$ includes 1.0 , then the risk reduction or increase is not statistically significant.

\section{DISCUSSION}

This follow-up study after approximately 26 years showed that the group with the most favourable lifestyle had a significantly lower risk for fatal and non-fatal CVD but not for cancer. The group with most favourable biological risk markers had a significantly lower risk for both fatal and non-fatal CVD and cancer. Men who were smokers or had high serum cholesterol at the baseline

Table 2 Risk reduction or risk increase presented as OR and $95 \%$ Cls for cardiovascular disease inclusive death

\begin{tabular}{lll}
\hline Cardiovascular disease & OR & 95\% Cls \\
\hline Summarised risk points in the health profile & & \\
$\quad$ Low-risk vs high-risk group & 0.34 & 0.16 to 0.71 \\
$\quad$ Middle-risk vs high-risk group & 0.86 & 0.52 to 1.42 \\
Lifestyle risk factors & 0.44 & 0.22 to 0.89 \\
$\quad$ Low-risk vs high-risk group & 0.63 & 0.38 to 1.05 \\
$\quad$ Middle-risk vs high-risk group & & \\
Biological risk factors & 0.31 & 0.15 to 0.66 \\
$\quad$ Low-risk vs high-risk group & 0.59 & 0.30 to 1.15 \\
Middle-risk vs high-risk group & & \\
Individual lifestyle and biological factors & 2.54 & 1.45 to 4.45 \\
Smoking: risk point 3-5 vs risk point 1-2 & 1.09 & 0.66 to 1.82 \\
Physical exercise: risk point 3-4 vs risk point 1-2 & 0.87 & 0.52 to 1.44 \\
Alcohol: risk point 2-3 vs risk point 1 & 0.75 & 0.27 to 2.07 \\
Alcohol: risk point 4-5 vs risk point 1 & 1.30 & 0.88 to 1.92 \\
BMl: risk point 3 vs risk point 1-2 & 1.69 & 0.78 to 3.67 \\
BMl: risk point 4-5 vs risk point 1-2 & 1.10 & 0.82 to 1.49 \\
Blood pressure: risk point 2 vs risk point 1 & 1.21 & 0.66 to 2.22 \\
Blood pressure: risk point 3-5 vs risk point 1 & 1.47 & 1.05 to 2.04 \\
Serum cholesterol: risk point 2 vs risk point 1 & 2.15 & 1.11 to 4.16 \\
Serum cholesterol: risk point 3-5 vs risk point 1
\end{tabular}

The data are presented as comparisons between different groups, according to summarised selected risk points (lifestyle plus biological risk factors) in the health profile (low-risk 9-14, middle-risk 15-18 and high-risk group 19-29 risk points), summarised lifestyle or biological risk markers (low-risk 3-5, middle-risk 6-8 and high-risk group 9-14 risk points).

If the $\mathrm{Cl}$ includes 1.0 , then the risk reduction or increase is not statistically significant.

$\mathrm{BMI}$, body mass index. 
Table 4 Risk reduction or risk increase presented as OR and 95\% Cls for pharmacological treated diabetes, for comparisons between different risk groups according to the health profile

\begin{tabular}{lcc}
\hline Diabetes & OR & 95\% Cls \\
\hline Individual lifestyle and biological risk factors & & 2.35 \\
Smoking: risk point 3-5 vs risk point 1-2 & 0.66 & 1.16 to 4.76 \\
Physical exercise: risk point 3-4 vs risk point 1-2 & 1.03 & 0.36 to 1.22 \\
Alcohol: risk point 2-3 vs risk point 1 & 1.07 & 0.55 to 1.94 \\
Alcohol: risk point 4-5 vs risk point 1 & 3.46 & 0.30 to 3.78 \\
BMl: risk point 3 vs risk point 1-2 & 11.97 & 2.19 to 5.48 \\
BMl: risk point 4-5 vs risk point 1-2 & 1.23 & 4.78 to 30.01 \\
Blood pressure: risk point 2 vs risk point 1 & 1.50 & 0.86 to 1.76 \\
Blood pressure: risk point 3-5 vs risk point 1 & 1.35 & 0.73 to 3.08 \\
Serum cholesterol: risk point 2 vs risk point 1 & 1.81 & 0.89 to 2.05 \\
Serum cholesterol: risk point 3-5 vs risk point 1 & & 0.78 to 4.19 \\
\hline If the Cl includes 1.0, then the risk reduction or increase is not statistically significant. & \\
BMl, body mass index. &
\end{tabular}

examination had a significantly higher risk for CVD. Significant single risk factors to develop diabetes were smoking and overweight or obesity. Self-estimated physical exercise during leisure time measured as in the health profile had no significant association to CVD, cancer and diabetes. When comparing the participants and non-participants, there was a significantly higher total mortality among the non-participants.

The strength in our study is a high baseline participation rate, and the long follow-up time of a rather young cohort of men together with individual follow-up data acquired from the Swedish National Board of Health and Welfare, and data from pharmacy register of sold drugs concerning diabetes mellitus. All data from the baseline examination and these two registers were based on personal code number.

There are some limitations in the follow-up study. The cohort is rather small and therefore the different CVD and cancer diagnoses were grouped together. The relative importance for the potential risk factors could be different in relation to the different diagnoses. The risk for CVD and cancer are only analysed in association to selected risk factors included in the health profile. There are several other risk factors for CVD and cancer, for example, food habits. In the questionnaire used in the baseline health examination, there were only four questions about food habits and these were not indexed in the health profile. We have only registration of lifestyle and biological risk markers at one occasion, and many men have probably changed both lifestyle and biological risk markers during follow-up. According to the British Regional Heart Study, these changes does not matter on group level, at least in a larger group. ${ }^{15}$

There can be several reasons why we could not show a significant risk for cancer among smokers in our study. The most frequent form of cancer in this study was prostate cancer, where smoking is not an established risk factor, and that cancer forms most related to smoking comes later in life. Many men, who were smokers at baseline, have probably stopped smoking. This is a national trend in Sweden during these years. ${ }^{18}$
Other studies have also shown an increased mortality among non-participants, mostly older at baseline. ${ }^{19}$ In a Finnish study of initially healthy businessmen 30-35 years at baseline with 28 years follow-up, total mortality was significantly higher among the non-participants. ${ }^{20}$ Coronary deaths were predicted by smoking, blood pressure and serum cholesterol. Our own study of the nonparticipant group at baseline showed that these men could be divided in three groups: those men who had already been to another health examination, those who already had contact with healthcare because of different illnesses and those who were not interested to participate at all. ${ }^{10}$ Men in this last mentioned group, $47 \%$ of the total non-participant group, were significantly more often registered at the temperance board, more often living alone and more unemployed during the past 2 years preceding the baseline examination in comparison with the participant group.

Other studies have shown that smoking is an established risk factor for CVD, cancer, diabetes and all-cause mortality. ${ }^{11} 15{ }^{21}$ High self-estimated physical activity is protective for GVD and cancer and lowers mortality. ${ }^{22} 23$ In the British Regional Heart Study, several of the established risk factors were predictive of CHD in 15 years of follow-up despite changes in risk factors measured in some individuals. ${ }^{15}$ The men in that study were $40-59$ years old at baseline. In a study of two Italian cohorts in the Seven Countries Study, many risk factors could predict mortality from CVD after 35 years of follow-up, for example, blood pressure, serum cholesterol, smoking and physical inactivity. ${ }^{24}$ These men were also 40-59 years at baseline. A younger cohort of men 18-39 years at baseline was followed for 25 years. Blood pressures at baseline were predictive of morbidity and mortality of CVD and all-cause mortality. ${ }^{25}$

In another study, the lifetime risk for total CVD was calculated. ${ }^{26}$ Those with optimal risk factor profile lived up to14 years longer than those with at least two major risk factors. This strengthens the importance to lower risk factor burden both through individual and community measures. An improved version of this health 
examination and dialogue was 'Live for Life' in primary health centres in the county of Skaraborg in Sweden. ${ }^{27}$ It was an intervention programme for men and women 30 and 35 years old. In the community of Habo where this intervention programme was most complete and combined with community intervention, premature mortality before the age of 75 decreased both in men and women more than in Sweden. ${ }^{28}$ Another successful Swedish example of an intervention programme in primary healthcare is the Västerbotten Intervention Programme. ${ }^{29} 30$

In conclusion, this study showed that favourable lifestyle and biological risk markers could predict morbidity and mortality from CVD and cancer after 26 years follow-up, even in this at baseline rather young group of men. The most important risk factors for CVD were smoking and serum cholesterol and for diabetes smoking and BMI.

Contributors L-GP is the principal author and responsible for the baseline study and the main contributor to the design of the present study. HL has given valuable contributions to the design and manuscript of the present study. MN has done the statistical analyses. SM is professor now in General Practice Lund University. When the follow-up study was designed, he was professor at the Unit for Research and Development in Primary Health Care Jönköping. He has given very valuable contributions to the design and manuscript of the present study.

Funding This work was supported by grants from FORSS (Medical Research Council of Southeast Sweden) and Futurum County Council of Jönköping Sweden.

\section{Competing interests None declared.}

Ethics approval Research Ethics Committee at Linköping University (Dnr A167-09).

Provenance and peer review Not commissioned; externally peer reviewed.

Data sharing statement The study data are avaible to L-GP the main author and MN the statistician.

Open Access This is an Open Access article distributed in accordance with the Creative Commons Attribution Non Commercial (CC BY-NC 4.0) license, which permits others to distribute, remix, adapt, build upon this work noncommercially, and license their derivative works on different terms, provided the original work is properly cited and the use is non-commercial. See: http:// creativecommons.org/licenses/by-nc/4.0/

\section{REFERENCES}

1. La Vecchia C, Levi F, Lucchini F, et al. Trends in mortality from major diseases in Europe, 1980-1993. Eur J Epidemiol 1998;14:1-8.

2. Sveriges officiella statistik. Statistik-Hälso- och Sjukvaård. Doödsorsaker 2012. [Official statistics of Sweden. Statistics-Health and Medical Care. Causes of Death 2012]. English summery. Stockholm: Socialstyrelsen, 2013.

3. Yusuf S, Hawken S, Ounpuu S, et al. Effect of potentially modifiable risk factors associated with myocardial infarction in 52 countries (the INTERHEART study): case-control study. Lancet 2004;364:937-52.

4. O'Donnell MJ, Xavier D, Liu L, et al. Risk factors for ischaemic and intracerebral haemorrhagic stroke in 22 countries (the INTERSTROKE study): a case-control study. Lancet 2010;376:112-23.

5. Coyle YM. Lifestyle, genes, and cancer. Methods Mol Biol 2009;472:25-56.

6. Khan N, Afaq F, Mukhtar $\mathrm{H}$. Lifestyle as risk factor for cancer: evidence from human studies. Cancer Lett 2010;293:133-43.

7. Conroy RM, Pyorala K, Fitzgerald AP, et al. Estimation of ten-year risk of fatal cardiovascular disease in Europe: the SCORE project. Eur Heart J 2003;24:987-1003.
8. Wilhelmsen L, Wedel H, Conroy R, et al. [The Swedish SCORE chart for cardiovascular risk. Better possibilities for prevention of cardiovascular diseases]. Lakartidningen 2004;101:1798-801.

9. Perk J, De Backer G, Gohlke H, et al. [European Guidelines on Cardiovascular Disease Prevention in Clinical Practice (version 2012). The Fifth Joint Task Force of the European Society of Cardiology and other societies on cardiovascular disease prevention in clinical practice (constituted by representatives of nine societies and by invited experts)]. G Ital Cardiol (Rome) 2013;14:328-92.

10. Persson LG, Lindström $\mathrm{K}$, Lingfors $\mathrm{H}$, et al. A study of men aged 33-42 in Habo, Sweden with special reference to cardiovascular risk factors. Design, health profile and characteristics of participants and non-participants. Scand J Soc Med 1994;22:264-72.

11. Doll R, Peto R, Boreham J, et al. Mortality in relation to smoking: 50 years' observations on male British doctors. BMJ 2004;328:1519.

12. Strandberg TE, Salomaa VV, Vanhanen HT, et al. Blood pressure and mortality during an up to 32-year follow-up. J Hypertens 2001;19:35-9.

13. Goldbourt U, Yaari S, Medalie JH. Factors predictive of long-term coronary heart disease mortality among 10,059 male Israeli civil servants and municipal employees. A 23-year mortality follow-up in the Israeli Ischemic Heart Disease Study. Cardiology 1993;82:100-21.

14. Clarke R, Emberson J, Fletcher A, et al. Life expectancy in relation to cardiovascular risk factors: 38 year follow-up of 19,000 men in the Whitehall study. BMJ 2009;339:b3513.

15. Wannamethee SG, Shaper AG, Whincup PH, et al. Role of risk factors for major coronary heart disease events with increasing length of follow up. Heart 1999;81:374-9.

16. Saltin B, Grimby G. Physiological analysis of middle-aged and old former athletes. A comparision with still active athletes of the same ages. Circulation 1968;38:1104-15.

17. Persson LG, Lindström K, Lingfors $\mathrm{H}$, et al. Results from an intervention programme dealing with cardiovascular risk factors. Experiences from a study of men aged 33-42 in Habo, Sweden. Scand J Prim Health Care 1996;14:184-92.

18. Wilhelmsen L, Welin L, Svardsudd K, et al. Secular changes in cardiovascular risk factors and attack rate of myocardial infarction among men aged 50 in Gothenburg, Sweden. Accurate prediction using risk models. J Intern Med 2008;263:636-43.

19. Larsen SB, Dalton SO, Schuz J, et al. Mortality among participants and non-participants in a prospective cohort study. Eur $J$ Epidemiol 2012;27:837-45.

20. Strandberg TE, Salomaa VV, Vanhanen HT, et al. Mortality in participants and non-participants of a multifactorial prevention study of cardiovascular diseases: a 28 year follow up of the Helsinki Businessmen Study. Br Heart J 1995;74:449-54.

21. The Health Consequences of Smoking-50 Years of Progress. A report of the Surgeon General. Executive summery. Atlanta, GA USA: Department of Health and Human Services, Centers for Disease Control and Prevention, 2014.

22. Rosengren A, Wilhelmsen L. Physical activity protects against coronary death and deaths from all causes in middle-aged men. Evidence from a 20-year follow-up of the primary prevention study in Goteborg. Ann Epidemiol 1997;7:69-75.

23. Sofi F, Capalbo A, Cesari F, et al. Physical activity during leisure time and primary prevention of coronary heart disease: an updated meta-analysis of cohort studies. Eur J Cardiovasc Prev Rehabil 2008;15:247-57.

24. Menotti A, Giampaoli S. A single risk factor measurement predicts 35-year mortality from cardiovascular disease. G Ital Cardiol 1998;28:1354-62.

25. Miura K, Daviglus ML, Dyer AR, et al. Relationship of blood pressure to 25-year mortality due to coronary heart disease, cardiovascular diseases, and all causes in young adult men: the Chicago Heart Association Detection Project in Industry. Arch Intern Med 2001;161:1501-8.

26. Wilkins JT, Ning $\mathrm{H}$, Berry J, et al. Lifetime risk and years lived free of total cardiovascular disease. JAMA 2012;308:1795-801.

27. Persson LG, Lindström $\mathrm{K}$, Lingfors $\mathrm{H}$, et al. Cardiovascular risk during early adult life. Risk markers among participants in "Live for Life" health promotion programme in Sweden. J Epidemiol Community Health 1998;52:425-32.

28. Lingfors H, Persson LG, Lindström K, et al. Time for a "vision zero" concerning premature death from ischaemic heart disease? Scand J Prim Health Care 2002;20:28-32.

29. Long GH, Simmons RK, Norberg M, et al. Temporal shifts in cardiovascular risk factor distribution. Am J Prev Med 2014;46:112-21.

30. Norberg M, Wall S, Boman K, et al. The Västerbotten Intervention Programme: background, design and implications. Glob Health Action 2010;3:1-15. 